Original article

\title{
Effect of an alcohol-free beer enriched with isomaltulose and a resistant dextrin on insulin resistance in diabetic patients with overweight or obesity
}

\author{
Rocío Mateo-Gallego ${ }^{\text {a, b }}$, Sofía Pérez-Calahorra ${ }^{a}$, Itziar Lamiquiz-Moneo ${ }^{\text {a, * }}$, \\ Victoria Marco-Benedí ${ }^{\mathrm{a}}$, Ana M. Bea ${ }^{\mathrm{a}}$, Antonio J. Fumanal ${ }^{\mathrm{c}}$, Ascensión Prieto-Martín ${ }^{\mathrm{c}}$, \\ Martín Laclaustra $^{\text {a, d }}{ }^{\text {, Ana Cenarro }}{ }^{a}$, Fernando Civeira ${ }^{\text {a, b }}$ \\ ${ }^{a}$ Hospital Universitario Miguel Servet, Instituto de Investigación Sanitaria Aragón (IIS Aragón), CIBERCV, Zaragoza, Spain \\ ${ }^{\mathrm{b}}$ Universidad de Zaragoza, Zaragoza, Spain \\ c Grupo Ágora - La Zaragozana S.A., Zaragoza, Spain \\ d Fundación Aragón Investigación y Desarrollo (ARAID), Zaragoza, Spain
}

\section{A R T I C L E I N F O}

\section{Article history:}

Received 13 August 2018

Accepted 16 February 2019

\section{Keywords:}

Alcohol-free beer

Isomaltulose

Resistant dextrin

Type 2 diabetes

Obesity

Insulin resistance

\begin{abstract}
S U M M A R Y
Background \& aims: The quality of carbohydrates has an essential role in nutritional management of type 2 diabetes mellitus (T2DM) because of its substantial impact on glucose homeostasis. Alcohol-free beer has beneficial bioactive components but it has a relatively high glycemic-index so its consumption is restricted in diabetic subjects. We aimed to explore the effect of an alcohol-free beer with modified carbohydrate composition almost completely eliminating maltose and adding isomaltulose (16.5 g/day) and a resistant maltodextrin ( $5.28 \mathrm{~g} /$ day) in comparison to a regular alcohol-free beer on glycemic control of diabetic subjects with overweight or obesity.

Design: We randomized 41 subjects into two groups: a) consumption of $66 \mathrm{cL} /$ day of; regular alcoholfree beer for the first 10 weeks and $66 \mathrm{cL} /$ day of alcohol-free beer with modified carbohydrate composition for the next 10 weeks; b) the same described intervention in opposite order. There was a washout period for 6-8 weeks between the two interventions. Participants were counseled to adhere to a healthy diet for cardiovascular health and to increase physical activity. Clinical, biochemical, anthropometric, lifestyle and satiety assessments were performed at the beginning and at the end of each period.

Results: Subjects showed significantly weight loss after the two ten weeks periods $(-1.69 \pm 3.21 \%$ and $-1.77 \pm 3.70 \%$ after experimental and regular alcohol-free beers, respectively, $P=0.881$ ). Glucose and glycated hemoglobin did not significantly change after any period. Insulin concentrations and HOMA-IR significantly decreased $(-11.1[-21.3-4.64] \%$ and $-1.92 \pm 32.8 \%$ respectively) after the intake of experimental alcohol-free beer but not after regular alcohol-free beer. Reductions remained statistically significant after adjusting for weight loss, energy intake, physical activity and intervention order. Subjects reported higher satiety scores after consuming experimental alcohol-free beer.

Conclusions: An alcohol-free beer including the substitution of regular carbohydrates for low doses of isomaltulose and the addition of a resistant maltodextrin within meals led to an improvement in insulin resistance in subjects with T2DM and overweight or obesity.

Clinical trial registration: The clinical trial has been registered in ClinicalTrials.gov (Identifier: NCT03337828).
\end{abstract}

(C) 2019 Elsevier Ltd and European Society for Clinical Nutrition and Metabolism. All rights reserved.

Abbreviations: AST, Aspartate transaminase; BMI, Body mass index; CRP, C-reactive protein; GGT, Gamma-glutamyl transferase; GI, Glycemic index; GLP-1, Glucagon-like

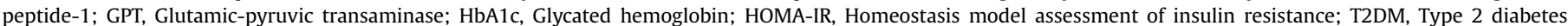
mellitus; VAS, Visual analogic scale.

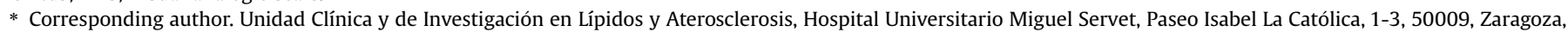
Spain. Fax: +34 976369985.

E-mail address: itziarlamiquiz@gmail.com (I. Lamiquiz-Moneo). 


\section{Introduction}

Diabetes mellitus burden is becoming a cause of concern due to its rapidly increasing global prevalence, complications and the excessive mortality rate which follows from its diagnosis [1,2]. Lifestyle intervention is a key issue in diabetes management and includes, among other aspects, medical nutrition therapy [3]. In the presence of overweight or obesity, weight loss constitutes one of the key objectives of treatment. However, there is limited evidence on the optimal diet to control hyperglycemia and obesity in type 2 diabetes mellitus (T2DM). The amount and type of carbohydrate is one of the cornerstones in nutrition therapy of T2DM patients since they commonly comprise fifty percent or more of all calories consumed, and they have a substantial impact on glucose homeostasis [4]. The effect of low-carbohydrate diets in patients with T2DM remains unclear $[3,5,6]$. Beyond the quantity, carbohydrate composition directly impacts postprandial glucose control [7]. The metabolic effects of carbohydrate-containing foods are determined, mainly, by their content of sugars, dietary fiber, glycemic responses to digestion, processing and whole-grain content. Several clinical trials have documented the beneficial effect of low-glycemic index (GI) diets on glycemic control in T2DM [8]. More recently, several studies have demonstrated that the impact of carbohydrates on insulin secretion and postprandial glycemia can substantially change depending on the types of foods with which the carbohydrates are consumed [9].

Isomaltulose, a disaccharide composed of $\alpha-1,6$-linked glucose and fructose, was recently introduced as an alternative sugar with delayed digestion and absorption resulting in a low GI of 32 [10]. A relatively high isomaltulose consumption (over $20 \mathrm{~g}$ per day) leads to cardiometabolic benefits including glycemic control, macronutrient oxidation and improved lipid profile, both in healthy and in diabetic patients [11]. Resistant dextrin is a glucose polymer (rich in $\alpha-1,4$ and $\alpha-1,6$ linkages) derived from wheat or maize [12]. It is incompletely hydrolyzed and absorbed in the small intestine, while the majority is fermented in the colon. High doses ( $\geq 10 \mathrm{~g})$ of resistant dextrin induce beneficial effects on glycemic status, systemic inflammation, body weight, and body composition in humans [13-15]. To the best of our knowledge, no study has previously explored the potential synergistic beneficial effect of isomaltulose and resistant dextrin in glucose homeostasis of subjects with prediabetes or T2DM.

Beer is over $90 \%$ water while the rest of components are mainly carbohydrates (glucose polymers) and alcohol. As a product of cereals fermentation of cereals, beer has B-complex vitamins, in particular folate and choline, and trace amounts of minerals such as potassium, calcium and magnesium [16]. Beer composition also includes a range of polyphenols such as flavonoids and phenolic acids that have protective effects on cardiovascular health as measured by inflammatory biomarkers, among other biomarkers [17-20]. Beer is widely consumed and it is often a preferred drink both in social events and on a daily basis. However, beer is usually restricted in T2DM patients because of its high content of carbohydrates and alcohol [3,5]. Alcohol-free beer has the same bioactive compounds (although in lower concentrations) than regular beer, excluding the alcohol [16,21]. GI is estimated as 119 in regular beer and 80 in alcohol-free beer, which is similar to that of potatoes, white bread or rice. In this context, we aimed to explore the effects of an alcohol-free beer with modified carbohydrates (almost completely eliminating maltose and adding isomaltulose (16.5 g/day) and a resistant maltodextrin (5.28 g/ day)) on glycemic control (HOMA-IR as main outcome) in diabetic subjects who are overweight or obese, in comparison to an alcohol-free beer with regular composition to overcome the restrictions to regular beer for T2DM. A secondary and exploratory objective of the study was to address the effect of modified alcohol-free beer on satiety.

\section{Material and methods}

\subsection{Study design and subjects}

A randomized, controlled, double-blind design with two parallel groups was performed among volunteers of both sexes aged 18-80, with a body mass index (BMI) ranging from 25 to $40 \mathrm{~kg} / \mathrm{m}^{2}$ and steady weight $( \pm 4 \mathrm{Kg})$ in the previous 2 months. We included those subjects with any of the following criteria: a) Diagnosis of prediabetes or T2DM according to international guidelines (fasting glucose concentration $\geq 100 \mathrm{mg} / \mathrm{dL}$ and/or glycated hemoglobin (HbA1c) $\geq 5.7 \%$, and not taking antidiabetic drugs); b) Previous diagnosis of prediabetes or T2DM on stable dose of metformin for 2 months, regardless of glucose and/or HbA1c levels. We excluded those subjects with poorly controlled diabetes defined as HbA1c concentration over 7\%. Other exclusion criteria were: gluten intolerance, lipid-lowering drugs and/or supplements of sterols or omega-3 fatty acids, weight loss medications, kidney disease (glomerular filtration rate $<45 \mathrm{~mL} / \mathrm{min}$ ), active liver disease, uncontrolled hypothyroidism, and any other disease or condition that could limit the study compliance.

\subsection{Recruitment and pre-screening}

Volunteers were recruited by public advertisements on local television and newspapers. They were invited to an informative session in which study objectives, and inclusion and exclusion criteria were explained in depth. Participants willing to participate completed a questionnaire that included: body weight, height, medical history, common medications, and availability to participate. Those volunteers who completed the study questionnaire and were eligible according to the inclusion and exclusion criteria were scheduled for a pre-screening visit. The visit was performed to assess eligibility criteria. It included clinical and anthropometric measurements to confirm that participants met BMI and other clinical criteria like gluten tolerance or pharmacological use, among others. We reviewed the most recently ( $<2$ months) glucose and HbA1c concentrations to check inclusion and exclusion criteria. If not available, we performed a blood extraction collection to assess these values according to the described methodology. If participant was eligible to enter the study, they were provided with dietary and exercise counseling and a randomization visit was scheduled 2-4 weeks later. We aimed to stabilize the lifestyle among participants during the entire study. Informed consent was obtained at this visit (Fig. 1).

The trial was carried out in the Clinical and Research Unit on Lipids and Atherosclerosis (Hospital Universitario Miguel Servet at Zaragoza (Spain)) from February 2017 to December 2017. The study protocol was approved by the local institutional ethical committee (Comité de Ética e Investigación Clínica de Aragón). All procedures were in accordance with the ethical standards of that committee. This clinical trial was registered in ClinicalTrials.gov under identifier NCT03337828.

\subsection{Randomization and intervention}

Participants were randomized into two groups (Fig. 1): a) consumption of two bottles ( $33 \mathrm{cL}$ each) per day of alcohol-free beer with regular composition for the first 10 weeks and two bottles ( $33 \mathrm{cL}$ each) per day of alcohol-free beer with modified carbohydrates 


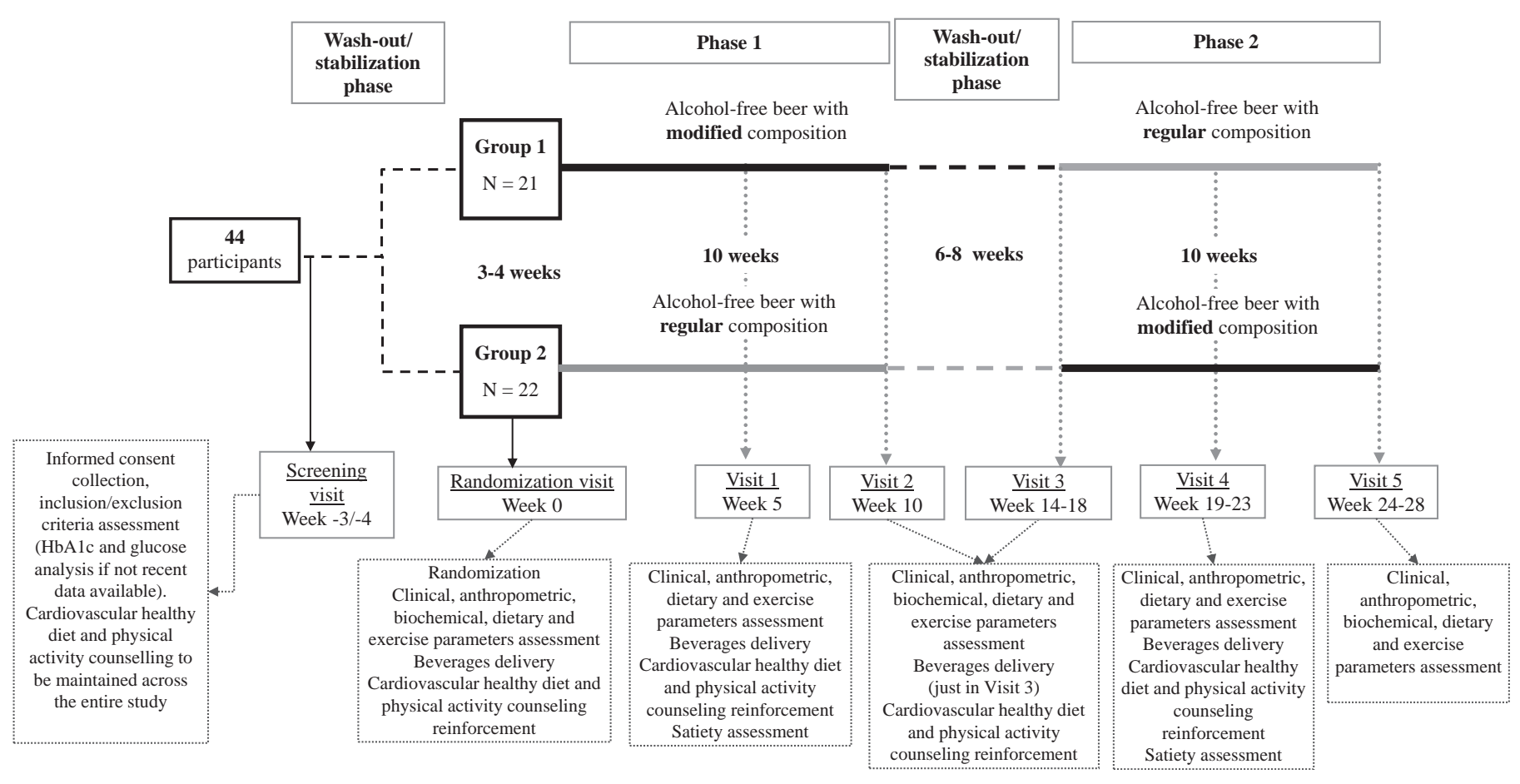

Fig. 1. Study design description.

composition for the next 10 weeks; b) the same described intervention in opposite order. There was a washout phase for $6-8$ weeks between the two intervention phases, during which time no beer was consumed. Alcohol-free beer with modified carbohydrates included a complete fermentation which almost completely eliminated maltose $(0.07 \mathrm{~g} / 100 \mathrm{~mL})$ and the addition of isomaltulose $(2.5 \mathrm{~g} / 100 \mathrm{~mL})$ and resistant maltodextrin $(0.8 \mathrm{~g} / 100 \mathrm{~mL})$. The participants received $16.5 \mathrm{~g}$ per day of isomaltulose and $5.28 \mathrm{~g}$ per day of resistant dextrin. The complete nutritional composition of both alcohol-free beers is provided in Supplemental Table 1.

Alcohol-free beers were provided to participants without charge and they were counseled to take the beers within main meals (lunch and dinner). Volunteers and research staff were blinded to the type of beer that individuals were assigned to consume in each phase. A local brewery prepared the beers in similar containers to maintain the blinding which was only revealed after the results were analyzed. Randomization was performed by using online software which generated a sequence of 44 numbers. Study numbers were correlatively assigned to the participants and they were assigned to a different intervention order based on the computer generated sequence. Participants were asked to fill in a daily questionnaire by recording all beers they consumed during the study. If they skipped any prescribed beer, it was recorded together with the reason on the beer was not consumed. The questionnaire was reviewed by a researcher on each visit who recorded consumption compliance. Participants were urged not to consume other beers (both with alcohol and alcohol-free) during the entire study.

Clinical, anthropometric and biochemical parameters along with dietary and physical activity information were collected at the following visits: randomization, end of the first phase, beginning of the second phase and end of the second phase (Fig. 1). Intermediate visits including clinical and anthropometric measurements and dietary and physical activity assessments were performed in the middle of each phase. These mid-phase visits intended to monitor the study intervention and to reinforce lifestyle intervention.

\subsection{Diet and physical activity}

Eligible participants were provided with counseling on cardiovascular healthy diet at pre-screening visits and at each study visit. Dietary counseling included established recommendations for subjects with T2DM and overweight or obesity. Advise included higher consumption of fruits, vegetables, whole-grains, low-fat dairy products and nuts and lower intake of red and processed meats, sweetened soft-drinks, alcohol, sweets or snacks. Illustrative sized portions were shown according to each participant's energy requirements to try to achieve a restriction of calorie consumption. All participants were provided with general physical-activity advice that was in accordance with their physical status. Physical activity advice was quite heterogeneous due to the different fitness conditions of subjects (i.e.: walk one hour a day or running $30 \mathrm{~min}$ three times a week).

Diet and physical activity were monitored across the study to control lifestyle factors that could interfere in the study findings. Participants were asked to complete a 3-day weighed food record before each visit. Dietary analysis was performed by an open source online tool (@ InsideMyFood.com) which is based on Spanish foodcomposition tables [22]. The International Physical Activity Questionnaire (IPAQ), a brief validated exercise questionnaire, was administered by direct interview from the researcher to the participant [23].

\subsection{Satiety questionnaire}

Participants were instructed to complete a satiety questionnaire 60-90 min after drinking one of the alcohol-free beers along with the eating food. We asked the volunteers to fill it in at 4 timepoints: once during the first 5 weeks of each phase and once during the last 5 weeks. The questionnaire was based on visual analogic scales (VAS) by including 8 questions regarding satiety and fullness. It included $100 \mathrm{~mm}$ horizontal lines anchored with the extremes of the subjective feeling of hunger to be quantified (i.e.: 
"not at all hungry" $(0 \mathrm{~mm}))$ and "as hungry as I have ever felt" $(100 \mathrm{~mm})$. This scale is commonly used and validated to measure appetite sensations and it is known to have good repeat reliability between groups [24]. Subjects were asked to record the amounts and times of eating all foods in the last 3 days. These amounts were analyzed in relation to the consumption of the different beers and to the proportions of calories, proteins, carbohydrates and fats consumed. This data was analyzed by an open source software, as previously explained.

\subsection{Anthropometric and clinical parameters}

Body weight was measured in subjects without shoes to the nearest $0.1 \mathrm{~kg}$ with a calibrated scale (Seca 813 , Seca Deutschland $\AA$, Hamburg, Deutschland). Height was assessed to the nearest $0.1 \mathrm{~cm}$ with a wall-mounted stadiometer (Seca 217, Seca Deutschland ${ }^{\circledR}$, Hamburg, Deutschland). BMI was calculated as weight in kilograms divided by the square of height in meters. Waist circumference was measured with anthropometric tape midway between the lowest rib and the iliac crest. Body composition was assessed via bioelectrical impedance through the bipolar foot-to-foot technique (Tanita TBF 410 GS, Omron Corporation ${ }^{\circledR}$, Tokyo, Japan) [25]. All measurements were taken in accordance with the recommended guidelines: no food or drink $3 \mathrm{~h}$ prior to measurements, no exhausting exercise $12 \mathrm{~h}$ prior to measurements, and no alcohol or caffeine consumption $24 \mathrm{~h}$ prior to measurements. Blood pressure was measured in triplicate with a validated semiautomatic oscillometer (Omron M3, Omron Cop; Hoofdorp, the Netherlands).

\subsection{Laboratory measurements}

Blood samples were drawn by venipuncture after $12 \mathrm{~h}$ fasting. The levels of total cholesterol, triglycerides, and HDL cholesterol, uric acid, gamma-glutamyl transferasa (GGT), glutamic-pyruvic transaminase (GPT) and aspartate transaminase (AST) were measured with standard enzymatic methods. LDL cholesterol levels were calculated with the Friedewald formula when serum triglycerides were $<400 \mathrm{mg} / \mathrm{dL}$. Non-HDL cholesterol was calculated as total cholesterol minus HDL cholesterol. Blood glucose concentration was measured with the glucose-oxidase method. Insulin levels were measured via radioimmunoassay. The homeostasis model assessment of insulin resistance (HOMA-IR) was estimated using fasting serum glucose $(\mathrm{mg} / \mathrm{dL}) \times$ plasma insulin $(\mu \mathrm{U} / \mathrm{mL}) / 405$. HbA1c was determined via high-performance liquid chromatography. C-reactive protein (CRP) was determined by nephelometry using IMMAGE-Immunochemistry System (Beckman Coulter, USA).

\subsection{Statistical analyses}

HOMA-IR was established as the main outcome and its variability was estimated at 1.5 units. We expected a difference of HOMA-IR of 0.70 among intervention groups after dietary intervention. A total sample size of 41 subjects was obtained by considering $80 \%$ power $(Z \beta$ unilateral $=0.842$ ) to detect a difference between treatment groups and a confidence interval $(1-\alpha)$ of $90 \%$ ( $Z \alpha$ unilateral $=1.282$ ). All subjects who completed the study were included in the data analysis, independent of reported intervention compliance according to intention-to-treat analysis. Continuous variables are expressed as mean \pm SD or median (25th percentile 75th percentile) as applicable and categorical (nominal) variables are reported as percentages of total sample. Differences between independent variables were calculated by $t$-test or Mann-Whitney test, as appropriate, while categorical variables were compared using the chi-squared test. Two-tailed $t$ tests or the Wilcoxon ranksum test for paired samples as appropriate were used to compare changes in outcome variables in response to each alcohol-free beer. Differences between both alcohol-free beers across the study were tested using linear mixed-effects models by including the 4 study time-points. To examine whether there was any carryover effect from intervention order and clinical and biochemical changes across the study, we used multiple linear regressions by including potential confounding factors (weight loss, energy intake and physical activity after intervention, and intervention order) as independent variables and study outcomes as dependent variables. All statistical analyses were performed with SPSS version 20.0 (SPSS Inc., Chicago, IL, USA) and R version 3.4.3 and significance was set at $P<0.05$.

\section{Results}

\subsection{Participants and study course}

A total of 57 participants were examined for eligibility of which 43 met all inclusion/exclusion criteria. Just one participant (a man beginning with alcohol-free beer with regular composition) dropped out of the study because of personal reasons and he was not included in the final analysis. As shown in Table 1, those participants assigned to one of the two study intervention sequences did not differ in terms of clinical or biochemical characteristics at baseline $(P>0.05$ for all parameters). Participants were mostly middle-aged $(55.8 \pm 7.41$ years $)$ with a mean BMI of $31.9 \pm 3.09 \mathrm{~kg} /$ $\mathrm{m}^{2}$ and there were more men than women in both groups. Glucose, insulin, HOMA-IR and HbA1c concentrations were $111 \pm 18.6 \mathrm{mg} /$ $\mathrm{dL}, 9.90 \pm 3.84 \mathrm{mg} / \mathrm{dL}, 2.70 \pm 1.10$ and $6.01 \pm 0.59 \%$, respectively, at the beginning of the study. Eight participants were taking metformin in stable doses during the whole study. The percentage of volunteers taking metformin did not significantly differ between those participants beginning with alcohol-free beer with modified composition $(\mathrm{N}=6)$ and those starting by alcohol-free beer with regular composition $(\mathrm{N}=2)$.

We observed a high compliance in beer consumption in both intervention periods. Subjects reported 96.2\% (95\% CI: 94.8-97.5) compliance during the period of consuming alcohol-free beer with regular composition and 96.7\% (95\% CI: 95.5-97.8) compliance during the period of consuming alcohol-free beer with modified carbohydrates composition. High compliance was constant across the study: $97.3 \%$ (95\% CI: 96.1-98.4) at the intermediate visit and 95.2\% (95\% CI: 93.1-97.2) at the final visit in the regular alcohol-free beers intervention period; and 97.1\% (95\% CI: 96.0-98.2) at the intermediate visit and 96.3\% (95\% CI: 94.7-97.8) at the final visit in modified composition alcohol-free beer period. The sequence of study intervention did not significantly influence the compliance.

\subsection{Weight loss and body composition}

Subjects showed a significant weight loss in both interventions: $-1.69 \pm 3.21 \%(P=0.004)$ in the period of consuming the alcohol-beer with modified carbohydrates composition and $-1.77 \pm 3.70 \%(P=0.007)$ in the period of consuming the regular alcohol-free beer (Table 2). Weight loss did not significantly differ between consumption periods of the two alcohol-free beers according to intervention order (data not shown). A similar significant decrease was observed in waist circumference after both intervention periods while no significant change was observed in body composition in any phase.

\subsection{Glucose metabolism parameters}

As indicated in Table 2 and in Fig. 2, blood glucose levels did not significantly change in any phase. HbA1c slightly decreased after 
Table 1

Clinical and biochemical characteristics at baseline according to dietary intervention sequence. ${ }^{\mathrm{a}}$

\begin{tabular}{|c|c|c|c|}
\hline & $\begin{array}{l}\text { Alcohol-free beer with regular composition } \rightarrow \text { Alcohol-free beer } \\
\text { with modified composition sequence } \\
\mathrm{N}=22\end{array}$ & $\begin{array}{l}\text { Alcohol-free beer with modified composition } \rightarrow \text { Alcohol-free beer } \\
\text { with regular composition sequence } \\
N=21\end{array}$ & $P^{\mathrm{b}}$ \\
\hline Age, years & $55.7 \pm 8.68$ & $55.9 \pm 6.03$ & 0.939 \\
\hline Gender, $\mathrm{n}(\%)$ males & $15(68.2)$ & $12(57.1)$ & 0.454 \\
\hline Weight, kg & $90.6 \pm 11.0$ & $88.8 \pm 11.8$ & 0.618 \\
\hline Waist circumference, $\mathrm{cm}$ & 113 [105-120] & 110 [105-113] & 0.265 \\
\hline Fat mass, kg & $31.0 \pm 7.12$ & $30.6 \pm 6.91$ & 0.885 \\
\hline Fat free mass, kg & $58.6 \pm 10.8$ & $57.5 \pm 9.72$ & 0.745 \\
\hline Visceral fat, levels & $13.9 \pm 3.42$ & $13.6 \pm 3.63$ & 0.809 \\
\hline $\begin{array}{l}\text { Systolic blood pressure, } \\
\text { mmHg }\end{array}$ & $130 \pm 16.9$ & $129 \pm 13.8$ & 0.927 \\
\hline $\begin{array}{l}\text { Diastolic blood pressure, } \\
\text { mmHg }\end{array}$ & $85.0 \pm 8.56$ & $84.3 \pm 9.21$ & 0.794 \\
\hline Metformin, $\mathrm{n}(\%)$ & $2(9.10)$ & $6(28.6)$ & 0.132 \\
\hline Total cholesterol, mg/dL & $208 \pm 34.1$ & $206 \pm 30.9$ & 0.815 \\
\hline HDL cholesterol, mg/dL & $51.2 \pm 7.90$ & $52.7 \pm 8.78$ & 0.575 \\
\hline Triglycerides, mg/dL & $111 \pm 46.3$ & $125 \pm 51.1$ & 0.211 \\
\hline LDL cholesterol, mg/dL & $134 \pm 27.6$ & $133 \pm 24.7$ & 0.824 \\
\hline Apolipoprotein B, mg/dL & $108 \pm 31.6$ & $114 \pm 28.3$ & 0.473 \\
\hline Glucose, mg/dL & $112 \pm 18.4$ & $110 \pm 19.1$ & 0.706 \\
\hline Insulin, mg/dL & $9.38 \pm 3.36$ & $10.4 \pm 4.24$ & 0.368 \\
\hline HOMA-IR & $2.57 \pm 0.91$ & $2.84 \pm 1.27$ & 0.419 \\
\hline HbA1c, \% & $5.98 \pm 0.67$ & $6.05 \pm 0.50$ & 0.700 \\
\hline GGT, U/L & $24.5[18.5-35.0]$ & $25.0[21.5-39.5]$ & 0.490 \\
\hline AST, U/L & $22.0[19.5-28.0]$ & $24.5[20.0-31.0]$ & 0.955 \\
\hline GPT, U/L & $23.3 \pm 8.91$ & $23.6 \pm 10.0$ & 0.905 \\
\hline Uric acid, mg/dL & $6.32 \pm 1.09$ & $6.15 \pm 1.80$ & 0.707 \\
\hline $\mathrm{CRP}, \mathrm{mg} / \mathrm{dL}$ & $0.17[0.08-0.36]$ & $0.27[0.15-0.48]$ & 0.198 \\
\hline
\end{tabular}

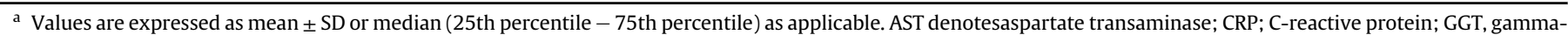
glutamyl transferase; GPT, gamma-glutamyl transaminase; HbA1c, glycated hemoglobin; HOMA-IR, Homeostasis model assessment of insulin resistance.

b $P$ refers to differences within each beer intervention period calculated by $\chi^{2}$ test, $t$-test or Mann-Whitney $U$ test as applicable.

both phases $-0.75 \pm 5.16 \%$ after regular alcohol-free beer consumption and $-1.11 \pm 4.61 \%$ after modified alcohol-free beer intake, with no differences within interventions $(P=0.500$ and $P=0.177$, respectively). We did find significant differences between both beers $(P=0.001$; Fig. 2$)$ although differences disappeared after adjusting by weight loss and other confounding factors. Insulin concentrations significantly decreased by $-11.1 \%(P=0.019)$ after the intake of experimental alcohol-free beer while no significant change was observed in the period consuming the regular beer $(P=0.812)$. We found statistically significant differences between diets $(P=0.043$; Fig. 2$)$ that remained significant after BMI change and order intervention adjustment $(P=0.001)$. However, the significance was lost in the fully adjusted model (BMI change, intervention order, gender, energy consumption, physical activity and fat mass change), $P=0.051$. HOMA-IR significantly decreased by $-1.92 \pm 32.8 \%(P=0.041)$ after consuming the modified alcohol-

Table 2

\begin{tabular}{|c|c|c|c|c|}
\hline & \multicolumn{2}{|c|}{ Alcohol-free beer with regular composition } & \multicolumn{2}{|c|}{ Alcohol-free beer with modified composition } \\
\hline & $\begin{array}{l}\Delta \% \text { change after intervention } \\
\mathrm{N}=43\end{array}$ & $P^{\mathrm{b}}$ & $\begin{array}{l}\Delta \% \text { change after intervention } \\
\mathrm{N}=42\end{array}$ & $P^{\mathrm{b}}$ \\
\hline Weight & $-1.77 \pm 3.70$ & 0.007 & $-1.69 \pm 3.21$ & 0.004 \\
\hline Waist circumference & $-2.87 \pm 4.40$ & 0.006 & $-1.55 \pm 2.45$ & 0.003 \\
\hline Fat mass & $-2.70 \pm 9.95$ & 0.112 & $-4.05 \pm 9.94$ & 0.167 \\
\hline Fat free mass & $-0.23 \pm 3.62$ & 0.833 & $-0.28 \pm 3.13$ & 0.142 \\
\hline Visceral fat & $0[-7.85-0]$ & 0.113 & $0[-8.33-0]$ & 0.243 \\
\hline Systolic blood pressure & $-2.93 \pm 8.84$ & 0.020 & $-1.46 \pm 9.55$ & 0.247 \\
\hline Diastolic blood pressure & $-3.70 \pm 8.62$ & 0.006 & $-3.65 \pm 9.17$ & 0.046 \\
\hline Total cholesterol & $2.02 \pm 10.8$ & 0.309 & $6.44 \pm 17.7$ & 0.050 \\
\hline HDL cholesterol & $1.38 \pm 9.72$ & 0.419 & $2.76 \pm 8.98$ & 0.047 \\
\hline Triglycerides & $9.17 \pm 33.8$ & 0.268 & $-0.41 \pm 30.9$ & 0.197 \\
\hline LDL cholesterol & $2.02 \pm 14.7$ & 0.550 & $5.41 \pm 19.7$ & 0.029 \\
\hline Apolipoprotein B & $-4.54[-9.60-15.8]$ & 0.881 & $1.06[-9.33-13.2]$ & 0.674 \\
\hline Glucose & $0.21 \pm 10.6$ & 0.503 & $1.26 \pm 12.2$ & 0.751 \\
\hline Insulin & $-1.64[-20.5-18.2]$ & 0.812 & $-11.1[-21.3-4.64]$ & 0.019 \\
\hline HOMA-IR & $10.4 \pm 59.6$ & 0.504 & $-1.92 \pm 32.8$ & 0.041 \\
\hline HbA1c & $-0.75 \pm 5.16$ & 0.500 & $-1.11 \pm 4.61$ & 0.177 \\
\hline GGT & $-3.70[-12.5-5.45]$ & 0.231 & $0.86[-15.7-6.70]$ & 0.566 \\
\hline AST & $-0.56 \pm 20.1$ & 0.326 & $6.01 \pm 18.5$ & 0.176 \\
\hline GPT & $-0.02 \pm 23.5$ & 0.269 & $9.28 \pm 34.2$ & 0.434 \\
\hline Uric acid & $-0.72 \pm 10.3$ & 0.377 & $-0.77 \pm 11.0$ & 0.175 \\
\hline CRP & $11.1[-32.2-50.0]$ & 0.688 & $0[-24.3-27.6]$ & 0.519 \\
\hline
\end{tabular}

a Values are expressed as mean + SD or median (25th percentile - 75th percentile) as applicable. AST denotes aspartate transaminase; CRP. C-reactive protein; GGT, gammaglutamyl transferase; GPT, gamma-glutamyl transaminase; HbA1c, glycated hemoglobin; HOMA-IR, Homeostasis model assessment of insulin resistance.

b $P$ refers to differences within each beer intervention period calculated by paired $t$-test or Wilcoxon test as applicable. 
free beer while regular alcohol-free beer intake did not lead to significant change $(10.4 \pm 59.6 \%, P=0.504)$. There was statistical significant differences in HOMA-IR change between both beers $(P<0.001)$ that remained significant after adjusting by BMI change, intervention order, gender, energy consumption, physical activity and fat mass change $(P=0.030)$.

\subsection{Other cardiometabolic parameters}

Systolic blood pressure significantly decreased just after the regular alcohol-free beer period while diastolic blood pressure significantly decreased after the consumption of both alcohol-free beers. There were not significant differences between the two alcohol-free beers in systolic $(P=0.203)$ and diastolic $(P=0.074)$ blood pressure after adjusting for BMI change, intervention order, gender, energy consumption, physical activity and fat mass change. LDL and HDL cholesterol slightly and significantly increased during the period of modified composition alcohol-free beer consumption while no significant change was observed during the regular alcoholfree beer period. LDL cholesterol varied from $135 \pm 25.2 \mathrm{mg} / \mathrm{dL}$ at baseline to $139 \pm 26.0 \mathrm{mg} / \mathrm{dL}$ at the end of intervention $(P=0.029)$ and HDL cholesterol increased from $52.5 \pm 8.74 \mathrm{mg} / \mathrm{dL}$ to $54.0 \pm 10.6 \mathrm{mg} / \mathrm{dL}(P=0.047)$. However, statistical differences disappeared after adjusting by all confounding factors (BMI change, intervention order, gender, energy consumption, physical activity and fat mass change; $P=0.104$ and $P=0.204$ for LDL and HDL, respectively). The rest of the biochemical parameters did not significantly change after any intervention.

\subsection{Dietary and physical activity parameters}

Dietary characteristics reported by participants across the study are included in Supplemental Table 2. Baseline dietary characteristics did not significantly differ between both phases $(P \geq 0.05$ for all dietary parameters). Participants did not report a significant change of energy intake in the period of consuming the regular alcohol-free beer. However, a significant decrease in energy intake at the intermediate visit in the period of consuming the experimental alcohol-free beer was observed $(P=0.013$ across intervention; $P=0.024$ comparing intermediate and final visits). The percentage of fat intake also decreased at the intermediate visit in the period in which participants were consuming modified composition alcohol-free beer $(P=0.023$ across intervention, $P=0.043$ comparing intermediate and final visits). This change was mainly observed at the expense of saturated fat $(P=0.007$ across interventions with experimental alcohol-free beer, $P=0.022$ comparing baseline and intermediate visits and $P=0.003$ comparing intermediate and final visits). Fiber and polyunsaturated fatty acid intake heterogeneously changed during regular composition alcohol-free beer period $(P=0.027$ and $P=0.017$ across interventions for fiber and polyunsaturated fatty acids, respectively).

Physical activity significantly differed at baseline between those subjects beginning with regular and those starting with experimental alcohol-free beer (1752 \pm 1305 and $961 \pm 732$ METS-h/week respectively, $P=0.025)$. However, baseline physical activity did not significantly differ between both periods $(P=0.140)$. During the study physical activity changed by $49.7 \pm 128 \%(P=0.569$ comparing baseline and the final visit) in the period consuming regular composition alcohol-free beer and it varied by $36.1 \pm 88.6 \%$ $(P=0.030$ comparing baseline and final visit) in the phase consuming modified composition alcohol-free beer. For that reason, we included physical activity change across the study in full-adjustment models previously described.

\subsection{Satiety assessment}

As reported in Table 3, participants reported a mean fullness score of $51.4 \pm 5.26$ (mean of the two satiety assessments during the
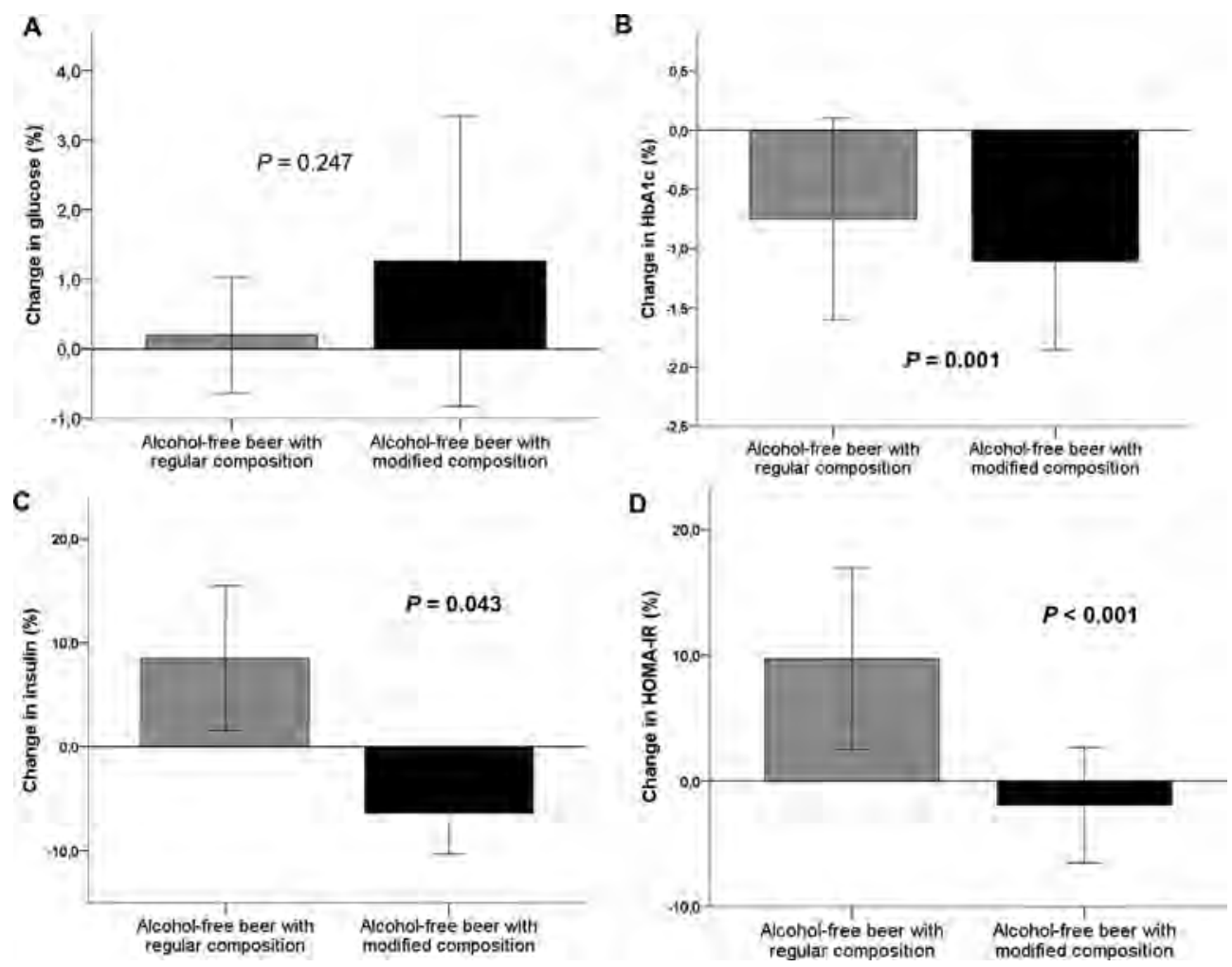

Fig. 2. Glucose metabolism parameters change after each alcohol-free beer. ${ }^{1}$ Statistical significance tested using linear mixed-effects models. 
intervention) after modified composition alcohol-free beer while this score was $48.5 \pm 8.55$ after the intake of regular alcohol-free beer ( $P=0.024$ comparing both beers). These values were adjusted by potential confounders: time since last alcohol-free beer consumption and carbohydrates, fiber, proteins and fat intake in the last meal. Subjects reported lower hunger scores (mean of $23.9 \pm 7.10$ between intermediate and final visits within intervention) after experimental alcohol-free consumption comparing to regular alcohol-free beer intake (mean of $26.9 \pm 7.49$ between intermediate and final visits within intervention), although no significant differences were denoted $(P=0.059)$. No differences were detected in others questions regarding appetite and desire for specific food types.

\subsection{Adverse events}

Subjects reported 31 non-severe adverse events across the study: 13 occurred during the period subjects were consuming the alcohol-free beer with modified composition and 18 during the period under regular alcohol-free beer intervention. Seven adverse events were related to mild gastrointestinal symptoms: 3 participants reported abdominal discomfort ( 2 during the modified beer consumption period and 1 during the regular beer consumption beer), 2 subjects reported constipation, 1 subject reported dyspepsia and 1 reported diarrhea. These last 5 adverse events were observed during the regular alcohol-free beer consumption period. All gastrointestinal adverse events were solved without requiring medication or any other medical intervention.

\section{Discussion}

The main finding of this randomized, double-blind and crossover study was that the consumption, within main meals, of $66 \mathrm{cL}$ per day of alcohol-free beer including the substitution of regular carbohydrates by isomaltulose ( $16.5 \mathrm{~g}$ per day) and the addition of a resistant maltodextrine ( $5.28 \mathrm{~g}$ per day) led to an improvement in insulin resistance in subjects with T2DM and overweight or obesity. This benefit was not denoted in while consuming regular alcohol-free beer and it was observed regardless of weight loss and other potential confounders like physical activity. Subjects reported higher satiety after consumption of modified composition alcohol-free beer in comparison with the regular alcohol-free beer consumption.

Different trials have revealed that isomaltulose decreases glucose and insulin concentrations and leads to an increase in fat oxidation in healthy, overweight and obese subjects [11,26-28]. Khalhöfer et al. reported a 28\% reduction in insulin secretion and 5\% in blood glucose levels in healthy men consuming $37 \mathrm{~g}$ of isomaltulose during 7 days [29]. However, the effect of this carbohydrate in subjects with T2DM has been barely explored. Brunner et al. did not observe significant changes in glucose metabolism after intake of $50 \mathrm{~g} / \mathrm{d}$ of isomaltulose during 12 weeks although they did denote a significant decrease in triglycerides compared with those participants consuming $50 \mathrm{~g} / \mathrm{d}$ of sucrose [30]. Another research study demonstrated that the ingestion of $1 \mathrm{~g} / \mathrm{kg}$-isomaltulose attenuated postprandial hyperglycemia by reducing oral glucose appearance and inhibiting endogenous glucose production, in comparison with the intake of rapidly absorbed sucrose in patients with T2DM [31]. Authors observed that isomaltulose decreased the mean plasma concentrations of insulin, C-peptide, glucagon, and glucose-dependent insulinotropic peptide by $10-23 \%$ in comparison with sucrose. Glucagon-like peptide-1 (GLP1 ) increased by $64 \%$ more and the cumulative amount of systemic glucose appearance was 35\% lower after isomaltulose than after sucrose consumption. Similar metabolic effects have also been described in healthy subjects [32].

To our knowledge, only two trials have determined the effect of resistant dextrin, which is a prebiotic, on glucose metabolism and both of them showed it to be beneficial. A clinical trial carried out in 60 healthy subjects showed a $18 \%$ decrease in plasma insulin after intake of $17 \mathrm{~g}$ of resistant dextrin which was statistically significantly higher than in controls [33]. A slightly higher glucose metabolism improvement was observed in 55 women with T2DM that were randomized to $10 \mathrm{~g}$ of resistant dextrin or placebo for 8 weeks. The researchers reported a significant $22.8 \%$ decrease in insulin, $24.9 \%$ in HOMA-IR, $0.6 \%$ in glucose and 9.6\% in HbA1c [13]. The benefits observed in glucose metabolism, weight loss and inflammation have been attributed to two different mechanisms. First, the supplementation with prebiotics has been demonstrated to favor the differentiation of L-cells which promote secretion of digestive hormones like GLP-1, peptide YY or gastric inhibitory polypeptide, among others [34]. Second, increased levels of endotoxins have been reported in diabetic patients [35]. Increased endotoxin levels like bacterial lipopolysacharides (metabolic endotoxaemia) lead to disturbances in appetite regulation and the expression of pro-inflammatory cytokines which are directly related to decrease in insulin action [36-38]. It has been proposed that resistant dextrin may contribute to the modulation of glycemic status by reducing body weight and inflammatory biomarkers through decreased metabolic endotoxaemia [13]. The modified alcohol-free beer provided in our study involved lower doses of isomaltulose and resistant dextrin than those used in prior research. However, we observed significant $-11.1 \%$ and $-1.92 \%$ decreases of insulin and HOMA-IR, respectively, which could be due

Table 3

Satiety assessment after each alcohol-free beer consumption. ${ }^{\mathrm{a}}$

\begin{tabular}{|c|c|c|c|c|c|c|c|}
\hline \multirow[t]{2}{*}{ Questions } & \multicolumn{3}{|c|}{ Alcohol-free beer with regular composition } & \multicolumn{3}{|c|}{ Alcohol-free beer with modified composition } & \multirow[t]{2}{*}{$P^{c}$} \\
\hline & $\begin{array}{l}\text { Intermediate visit } \\
\mathrm{N}=32\end{array}$ & $\begin{array}{l}\text { Final visit } \\
\mathrm{N}=32\end{array}$ & $\begin{array}{l}\text { Mean of both visits } \\
N=32\end{array}$ & $\begin{array}{l}\text { Intermediate visit } \\
\mathrm{N}=32\end{array}$ & $\begin{array}{l}\text { Final visit } \\
\mathrm{N}=32\end{array}$ & $\begin{array}{l}\text { Mean of both visits } \\
\mathrm{N}=32\end{array}$ & \\
\hline How hungry do you feel? & $31.3 \pm 7.74$ & $24.1 \pm 7.93$ & $26.9 \pm 7.49$ & $28.1 \pm 9.32$ & $20.4 \pm 5.85$ & $23.9 \pm 7.10$ & 0.059 \\
\hline How satisfied do you feel? & $50.4 \pm 8.78$ & $52.8 \pm 10.4$ & $52.4 \pm 9.71$ & $51.7 \pm 5.88$ & $53.5 \pm 8.32$ & $52.7 \pm 6.60$ & 0.443 \\
\hline How full do you feel? & $45.3 \pm 6.70$ & $49.4 \pm 10.7$ & $48.5 \pm 8.55$ & $52.6 \pm 4.81$ & $50.5 \pm 7.02$ & $51.4 \pm 5.26$ & 0.024 \\
\hline How much do you think you can eat? & $38.6 \pm 11.2$ & $42.6 \pm 15.4$ & $40.5 \pm 13.2$ & $37.4 \pm 8.94$ & $35.2 \pm 9.12$ & $36.4 \pm 6.97$ & 0.108 \\
\hline How strong is your desire to eat something sweet? & $59.6 \pm 13.4$ & $60.9 \pm 12.6$ & $60.7 \pm 10.3$ & $54.2 \pm 15.0$ & $63.1 \pm 12.4$ & $58.6 \pm 12.3$ & 0.477 \\
\hline How strong is your desire to eat something salty? & $55.1 \pm 13.4$ & $60.8 \pm 13.1$ & $58.9 \pm 12.6$ & $56.6 \pm 11.5$ & $64.2 \pm 6.89$ & $60.5 \pm 8.12$ & 0.793 \\
\hline How strong is your desire to eat something tasty? & $56.0 \pm 13.8$ & $61.1 \pm 11.6$ & $59.6 \pm 11.6$ & $55.5 \pm 9.86$ & $63.0 \pm 9.22$ & $59.8 \pm 8.51$ & 0.881 \\
\hline How strong is your desire to eat something fatty? & $78.1 \pm 8.98$ & $70.5 \pm 11.9$ & $73.0 \pm 10.6$ & $69.3 \pm 17.1$ & $74.18 \pm 6.97$ & $71.6 \pm 10.7$ & 0.808 \\
\hline
\end{tabular}

a Values are expressed as mean \pm SD. Questionnaire values have been adjusted by time since last alcohol-free beer consumption and carbohydrates, fiber, proteins and fat intake in the last meal.

b Mean of both visits refers to the mean between intermediate and final visit values in that period.

c $P$ refers to differences between the means in each alcohol-free beer period which is calculated by paired $t$ test. 
to a synergistic effect of both nutrients. The effects were lower than those previously reported in the studies above but that would be consistent with a dose-dependent effect of these components. Also, we advised the participants to take the alcohol-free beers with meals which could have played an essential role in findings by confirming the modulation of postprandial glycemia of both nutrients despite the low doses were used.

The participants reported higher satiety scores during the period of drinking the alcohol-free beer with isomaltulose and resistant dextrin than during the regular alcohol-free beer period. However, we did not find a differential effect of the two beers in weight loss. We observed a significant decrease in energy intake in the first 5 weeks that subjects consumed alcohol-free beer with modified composition but significance was lost at the end of that study period. Previous trials have reported that resistant dextrin increased satiety which was confirmed by key-appetite digestive hormones like ghrelin $[39,40]$. Despite previous research involving higher doses of both nutrients, their synergic effect could lead to a higher satiety effect. We hypothesized that we did not denote an enhanced-weight loss ability of modified alcohol-free beer because of an acute effect on satiety or because higher doses of both nutrients are needed. Anyway, the possible satiety enhance ability of the modified composition alcohol-free beer should be confirmed in future studies by including the assessment of more sensitive measurement of satiety and appetite biomarkers.

This study involved healthy lifestyle recommendations including slight energy intake restriction, a cardiovascular healthy dietary pattern (based on the Mediterranean diet) and an increase of physical activity. Subjects showed a $-1.77 \%$ mean weight loss after the phase of consuming a regular composition alcohol-free beer and $-1.69 \%$ after the period of consuming the experimental alcohol-free beer. Results demonstrated that inclusion of tasty and light foods does not prevent body weight reduction and could even be an incentive in weight loss management. Beyond calorie counting, a recent report proposed that high-glycemic-load carbohydrates produce hormonal changes that promote calorie deposition in adipose tissue, exacerbate hunger, and lower energy expenditure [41]. Thus, it is crucial to go in depth into approaches that ameliorate the negative influence of carbohydrates in commonly consumed foods.

Our study has some limitations worth mentioning. The midterm length of intervention design could have influenced findings, although previous interventional studies that have explored the effect of isomaltulose and resistant dextrin have a shorter time frame. The relatively small sample size could have limited the significance of the effect of the intervention in some outcomes and the extrapolation of findings. Although satiety has been explored by VAS, which has been previously validated, an objective measurement of appetite and satiety such as ghrelin or neuropeptide $Y$ assessment would be necessary to confirm our findings.

In conclusion, an alcohol-free beer including the substitution of regular carbohydrates by isomaltulose ( $16.5 \mathrm{~g}$ per day) and the addition of a resistant dextrin ( $5.28 \mathrm{~g}$ per day) within meals lead to an improvement of insulin resistance (insulin concentration and HOMA-IR) in subjects with T2DM and overweight or obesity. These effects were observed within a lifestyle intervention and regardless of weight loss, physical activity and other confounding factors. To our knowledge, this is the first study employing relatively low doses of isomaltulose and resistant dextrin that demonstrates that a synergic effect of these nutrients could modulate postprandial glycemia and improve glucose metabolism in subjects with T2DM. Improvement in carbohydrate quality in the diet is a cornerstone that merits further research based on its impact not only on glucose metabolism but in overall metabolism. The inclusion of this alcohol-free beer with modified carbohydrates composition could be part of a healthy diet by improving glycemia management but also increasing the palatability of nutritional therapy.

\section{Sources of support}

This study was supported by funding from Grupo Ágora - La Zaragozana S.A. It was also partially supported by a grant from the Carlos III Research Institute: CIBERCV (co-supported by the European Regional Development Fund (ERDF) which is allocated by the European Union; IIS16/0114).

\section{Conflict of interest}

None declared.

\section{Acknowledgments}

The authors thank the participants for their enthusiastic collaboration in the study and Brandi Reed and Cecilia Bennett for their English editorial assistance. Rocío Mateo-Gallego research activity is funded by Instituto Aragonés de Ciencias de la Salud (IACS), Itziar Lamiquiz-Moneo research activity is funded by Fundación Cuenca Villoro and Martín Laclaustra research activity is funded by Fundación Aragón Investigación y Desarrollo (ARAID).

Authors would like to state that A.F. and A.P.M. work for Grupo Ágora - La Zaragozana S.A., which has partially funded the study. They have provided help with logistics and research design but they did not interfere in blind analysis of results. Authors have no other relevant conflict of interest to disclose. Author contributions were as follows: R.M.G, conceptualization, data curation, formal analysis, investigation, methodology, writing the manuscript; S.P.C, data curation, investigation, formal analysis; V.M.B, A.M.B, I.L.M, M.L and A.C, data curation, investigation; A.F. and A.P.M, conceptualization, methodology and funding acquisition; F.C, conceptualization, formal analysis, investigation, methodology, writing the manuscript. All authors have reviewed and approved the final manuscript.

\section{Appendix A. Supplementary data}

Supplementary data to this article can be found online at https://doi.org/10.1016/j.clnu.2019.02.025.

\section{References}

[1] Hu FB. Globalization of diabetes: the role of diet, lifestyle, and genes. Diabetes Care 2011:34:1249-57.

[2] Ley SH, Hamdy O, Mohan V, Hu FB. Prevention and management of type 2 diabetes: dietary components and nutritional strategies. Lancet 2014;383: 1999-2007.

[3] American Diabetes Association. Lifestyle management: standards of medical care in diabetes-2018. Diabetes Care 2018;41:S38-50.

[4] Ajala O, English P, Pinkney J. Systematic review and meta-analysis of different dietary approaches to the management of type 2 diabetes. Am J Clin Nutr 2013;97:505-16.

[5] Wheeler ML, Dunbar SA, Jaacks LM, Karmally W, Mayer-Davis EJ, WylieRosett J, et al. Macronutrients, food groups, and eating patterns in the management of diabetes: a systematic review of the literature, 2010. Diabetes Care 2012;35:434-45.

[6] van Wyk HJ, Davis RE, Davies JS. A critical review of low-carbohydrate diets in people with Type 2 diabetes. Diabet Med 2016;33:148-57.

[7] Mozaffarian D. Dietary and policy priorities for cardiovascular disease, diabetes, and obesity: a comprehensive review. Circulation 2016;133:187-225.

[8] Thomas D, Elliott EJ. Low glycaemic index, or low glycaemic load, diets for diabetes mellitus. Cochrane Database Syst Rev 2009 Jan 21;(1):CD006296. https://doi.org/10.1002/14651858.CD006296.pub2.

[9] Meng H, Matthan NR, Ausman LM, Lichtenstein AH. Effect of macronutrients and fiber on postprandial glycemic responses and meal glycemic index and glycemic load value determinations. Am J Clin Nutr 2017;105:842-53.

[10] Lina BAR, Jonker D, Kozianowski G. Isomaltulose (Palatinose): a review of biological and toxicological studies. Food Chem Toxicol 2002;40:1375-81. 
[11] Maresch CC, Petry SF, Theis S, Bosy-Westphal A, Linn T. Low glycemic index prototype isomaltulose-update of clinical trials. Nutrients 2017;9.

[12] Lefranc-Millot C. NUTRIOSE $\Re$ 06: a useful soluble dietary fibre for added nutritional value. Nutr Bull 2008;33:234-9.

[13] Aliasgharzadeh A, Dehghan P, Gargari BP, Asghari-Jafarabadi M. Resistant dextrin, as a prebiotic, improves insulin resistance and inflammation in women with type 2 diabetes: a randomised controlled clinical trial. Br J Nutr 2015;113:321-30.

[14] Guerin-Deremaux L, Ringard F, Desailly F, Wils D. Effects of a soluble dietary fibre NUTRIOSE $®$ on colonic fermentation and excretion rates in rats. Nutr Res Pract 2010;4:470-6.

[15] [Internet] Dose-response impact of a soluble fiber, NUTRIOSE ${ }^{\circledR}$, on energy intake, body weight and body fat in humans. ALS; 2013 [cited 2018 Jul 23]. Available from: https://www.sprim-als.com/es/dose-response-impact-ofsoluble-fiber-nutriose-energy-intake-body-weight-and-body-fat-humans/.

[16] de Gaetano G, Costanzo S, Di Castelnuovo A, Badimon L, Bejko D, Alkerwi A, et al. Effects of moderate beer consumption on health and disease: a consensus document. Nutr Metab Cardiovasc Dis NMCD 2016;26:443-67.

[17] Pérez-Jiménez J, Neveu V, Vos F, Scalbert A. Identification of the 100 richest dietary sources of polyphenols: an application of the Phenol-Explorer database. Eur J Clin Nutr 2010;64(Suppl 3):S112-20.

[18] Costanzo S, Di Castelnuovo A, Donati MB, Iacoviello L, de Gaetano G. Wine beer or spirit drinking in relation to fatal and non-fatal cardiovascular events: a meta-analysis. Eur J Epidemiol 2011;26:833-50.

[19] Chiva-Blanch G, Magraner E, Condines X, Valderas-Martínez P, Roth I, Arranz S, et al. Effects of alcohol and polyphenols from beer on atherosclerotic biomarkers in high cardiovascular risk men: a randomized feeding trial. Nutr Metab Cardiovasc Dis 2015;25:36-45.

[20] Imhof A, Woodward M, Doering A, Helbecque N, Loewel H, Amouyel P, et al Overall alcohol intake, beer, wine, and systemic markers of inflammation in western Europe: results from three MONICA samples (Augsburg, Glasgow, Lille). Eur Heart J 2004;25:2092-100.

[21] Martínez Alvarez JR, Bellés VV, López-Jaén AB, Marín AV, Codoñer-Franch P. Effects of alcohol-free beer on lipid profile and parameters of oxidative stress and inflammation in elderly women. Nutrition 2009;25:182-7.

[22] Inside my food. Available at: http://www.insidemyfood.com/. Accessed June $16,2018$.

[23] Hagströmer M, Oja P, Sjöström M. The International Physical Activity Questionnaire (IPAQ): a study of concurrent and construct validity. Public Health Nutr 2006;9:755-62.

[24] Flint A, Raben A, Blundell JE, Astrup A. Reproducibility, power and validity of visual analogue scales in assessment of appetite sensations in single test meal studies. Int J Obes 2000;24:38-48.

[25] Linares CL, Ciangura C, Bouillot J-L, Coupaye M, Declèves X, Poitou C, et al. Validity of leg-to-leg bioelectrical impedance analysis to estimate body fat in obesity. Obes Surg 2011;21:917-23.

[26] König D, Theis S, Kozianowski G, Berg A. Postprandial substrate use in overweight subjects with the metabolic syndrome after isomaltulose (Palatinose $^{\mathrm{TM}}$ ) ingestion. Nutrition 2012;28:651-6.
[27] Takeda E, Yamanaka-Okumura H, Taketani Y, Inagaki N, Hosokawa M, Shide K, et al. Effect of nutritional counseling and long term isomaltulose based liquid formula (MHN-01) intake on metabolic syndrome. J Clin Biochem Nutr 2015;57:140-4.

[28] van Can JGP, Ijzerman TH, van Loon LJC, Brouns F, Blaak EE. Reduced glycaemic and insulinaemic responses following isomaltulose ingestion: implications for postprandial substrate use. Br J Nutr 2009;102:1408-13.

[29] Kahlhöfer J, Karschin J, Silberhorn-Bühler H, Breusing N, Bosy-Westphal A. Effect of low-glycemic-sugar-sweetened beverages on glucose metabolism and macronutrient oxidation in healthy men. Int J Obes 2016;40:990-7.

[30] Brunner S, Holub I, Theis S, Gostner A, Melcher R, Wolf P, et al. Metabolic effects of replacing sucrose by isomaltulose in subjects with type 2 diabetes: a randomized double-blind trial. Diabetes Care 2012;35:1249-51.

[31] Ang M, Linn T. Comparison of the effects of slowly and rapidly absorbed carbohydrates on postprandial glucose metabolism in type 2 diabetes mellitus patients: a randomized trial. Am J Clin Nutr 2014;100:1059-68.

[32] Maeda A, Miyagawa J-I, Miuchi M, Nagai E, Konishi K, Matsuo T, et al. Effects of the naturally-occurring disaccharides, palatinose and sucrose, on incretin secretion in healthy non-obese subjects. I Diabetes Investig 2013:4:281-6.

[33] Li S, Guerin-Deremaux L, Pochat M, Wils D, Reifer C, Miller LE. NUTRIOSE dietary fiber supplementation improves insulin resistance and determinants of metabolic syndrome in overweight men: a double-blind, randomized, placebo-controlled study. Appl Physiol Nutr Metab 2010;35:773-82.

[34] Cani PD, Lecourt E, Dewulf EM, Sohet FM, Pachikian BD, Naslain D, et al. Gut microbiota fermentation of prebiotics increases satietogenic and incretin gut peptide production with consequences for appetite sensation and glucose response after a meal. Am J Clin Nutr 2009;90:1236-43.

[35] Gomes JMG, de Costa JA, de Alfenas RCG. Metabolic endotoxemia and diabetes mellitus: a systematic review. Metabolism 2017;68:133-44.

[36] Cani PD, Amar J, Iglesias MA, Poggi M, Knauf C, Bastelica D, et al. Metabolic endotoxemia initiates obesity and insulin resistance. Diabetes 2007;56: $1761-72$.

[37] Luche E, Cousin B, Garidou L, Serino M, Waget A, Barreau C, et al. Metabolic endotoxemia directly increases the proliferation of adipocyte precursors at the onset of metabolic diseases through a CD14-dependent mechanism. Mol Metab 2013;2:281-91.

[38] Amar J, Burcelin R, Ruidavets JB, Cani PD, Fauvel J, Alessi MC, et al. Energy intake is associated with endotoxemia in apparently healthy men. Am J Clin Nutr 2008;87:1219-23.

[39] Nazare J-A, Sauvinet V, Normand S, Guérin-Deremaux L, Gabert L, Désage M, et al. Impact of a resistant dextrin with a prolonged oxidation pattern on daylong ghrelin profile. J Am Coll Nutr 2011;30:63-72.

[40] Guérin-Deremaux L, Pochat M, Reifer C, Wils D, Cho S, Miller LE. The soluble fiber NUTRIOSE induces a dose-dependent beneficial impact on satiety over time in humans. Nutr Res 2011;31:665-72.

[41] Ludwig DS, Ebbeling CB. The carbohydrate-insulin model of obesity: beyond "calories in, calories out". JAMA Intern Med. 2018 Aug 1;178(8):1098-103. https://doi.org/10.1001/jamainternmed.2018.2933. 